\title{
ADUBAÇÃO FOLIAR E VIA SOLO DE NITROGÊNIO EM PLANTAS DE MILHO EM FASE INICIAL DE DESENVOLVIMENTO
}

\author{
Leaf fertilization and via soil nitrogen suplementation in maize \\ plants at initial developmental stage
}

\begin{abstract}
Sidnei Deuner ${ }^{1}$, Ronaldo do Nascimento ${ }^{2}$, Ladislau Soares Ferreira ${ }^{3}$, Pablo Gerson Badinelli ${ }^{4}$, Romel Silva Kerber ${ }^{5}$
RESUMO

Considerado o nutriente mais importante, tanto no incremento da produção de grãos como no teor protéico destes, o nitrogênio $(\mathrm{N})$ é também o elemento que mais onera a cultura do milho. Neste trabalho, objetivou-se verificar se a aplicação foliar de nitrogênio influencia o acúmulo de proteínas e parâmetros de crescimento de plantas jovens de milho em comparação com a aplicação de uréia via solo. Para tanto, plantas jovens do híbrido de milho BR 206 receberam aplicações de uréia como fonte de $\mathrm{N}$ via foliar e via solo nas concentrações de zero; $0,5 \%$ e $1,0 \%$. As plantas foram cultivadas em casa-de-vegetação sendo realizadas três aplicações de $\mathrm{N}$, a primeira aos seis dias após a emergência (DAE) num volume de $10 \mathrm{~mL}$ por planta e as duas seguintes aos 10 e 14 DAE com 20 $\mathrm{mL}$ cada. Aos $18 \mathrm{DAE}$ as plantas foram coletadas e as análises procedidas. Para altura de plantas, volume radicular, área foliar, matéria seca da parte aérea e raízes, observou-se maior eficiência da adubação foliar, principalmente ao nível de $0,5 \%$ de uréia. O fornecimento de uréia a 1,0\% via solo proporcionou aumento significativo no teor de proteínas nas folhas. Tais resultados sugerem que a adubação foliar pode ser uma maneira eficiente para complementar o que é absorvido pelas raízes, no entanto não deve ser utilizada como fonte única de $\mathrm{N}$ inorgânico às plantas.
\end{abstract}

Termos para indexação: Uréia, fertilização foliar, Zea mays L.

\section{ABSTRACT}

Consider the most important nutrient in the increment of grain gield and also the proteic level, nitrogen $(\mathrm{N})$, in addition of this fact, this nutrient is the component that most increases the production cost of maize crop. This study aimed to verify whether the application of leaf nitrogen influences the accumulation of proteins and parameters of growth of young plants of maize compared to the application of urea via soil. For both, young plants of the hybrid maize BR 206 received applications of urea as a source of N via leaf and soil at concentrations of zero, $0.5 \%$ and $1.0 \%$. The plants were grown in a greenhouse being held three applications of $\mathrm{N}$, the first for six days after the emergency (DAE) in a volume of $10 \mathrm{ml}$ per plant and the following two to 10 and 14 DAE with $20 \mathrm{ml}$ each. At 18 DAE the plants were collected and analyses proceeded. For plant height, root volum, leaf area, dry weigth of leaf area and root, one verified a higher efficiency of leaf fertilization, mainly at $0,5 \%$ level of urea. The application of urea $1,0 \%$ via soil caused a significative increase in leaf protein levels. These results suggest that leaf fertilization may be an efficient mode to complement what is uptaken by the roots, although it should not be used as a unique source of inorganic $\mathrm{N}$ to the plants.

Index terms: Urea, leaf fertilization, Zea mays L.

(Recebido em 13 de setembro de 2006 e aprovado em 30 de maio de 2008)

\section{INTRODUÇÃO}

O milho (Zea mays L.) é uma das culturas de maior importância para o Brasil, não só do ponto de vista econômico, em função da extensa área cultivada, mas também nutricional, em razão da diversidade de utilização, em que se destacam a alimentação humana e animal
(DÖBEREINER et al., 1995). A eficiência do uso do nitrogênio $(\mathrm{N})$ em cereais no mundo é de apenas $33 \%$. Considerando os $67 \%$ de $\mathrm{N}$ que não são aproveitados, tem-se um custo anual substancial em fertilização nitrogenada (RAUN \& JOHNSON, 1999), em adição aos prováveis impactos negativos ao ambiente (SCHRÖDER et al., 2000).

\footnotetext{
${ }^{1}$ Engenheiro Agrônomo, Professor Dr., bolsista PRODOC - Universidade Federal de Pelotas/UFPel - Cx. P. 354 - $96010-900$ - Pelotas, RS sdeuner@yahoo.com.br

Engenheiro Agrônomo, Douotr em Fisiologia Vegetal, Professor Adjunto - Departamento de Botânica/DBI - Unidade Acadêmica de Serra Talhada Universidade Federal Rural de Pernambuco/UFRPE - Campus Universitário - Zona Rural - Cx. P. 063 - 56900-000 - Serra Talhada, PE ronascim@uast.ufrpe.br

${ }^{3}$ Engenheiro Agrônomo, Mestre em Fisiologia Vegetal - Monsanto do Brasil Ltda. - Rua Tiradentes, 314 - Centro - $08802-530$ - Santo Ângelo, RS ladislau.s.ferreira@monsanto.com

${ }^{4}$ Engenheiro Agrônomo, Mestrando em Fisiologia Vegetal - Departamento de Botânica - Instituto de Biologia - Universidade Federal de Pelotas/UFPel Campus Universitário, s/n - Cx. P. 354 - 96010-900 - Pelotas, RS - pbadinelli@hotmail.com

${ }^{5}$ Engenheiro Agrônomo - Cooperativa Agrícola Mista General Osório Ltda./COTRIBÁ - Avenida Presidente Vargas, 84 - $98240-000$ - Santa Bárbara do Sul, RS - romelsk @@hotmail.com
} 
$\mathrm{O} \mathrm{N}$ possui papel fundamental no metabolismo vegetal por participar diretamente na biossíntese de proteínas e clorofilas (ANDRADE et al., 2003). No entanto, encontra-se em quantidades insuficientes na maioria dos solos brasileiros, tornando-se crucial um fornecimento exógeno em concentração adequada para garantir o crescimento, desenvolvimento e a produtividade das plantas de milho (BELARMINO et al., 2003). Com esse conhecimento, minimizam-se as perdas e aumenta-se a eficiência do uso do N (BOTREL et al., 1999).

Em plantas de milho há uma intensa absorção de $\mathrm{N}$ nas fases iniciais de desenvolvimento, sendo a deficiência deste uma das maiores limitações à produtividade. $\mathrm{O}$ conhecimento dos processos envolvidos na incorporação e transformação do N no sistema solo-planta-atmosfera é imprescindível ao desenvolvimento de estratégias de manejo que aumentem o seu aproveitamento pelas culturas. No caso do milho, no cultivo que recebeu a aplicação, o aproveitamento raramente ultrapassa $50 \%$ do aplicado como fertilizante mineral (LARA CABEZAS et al., 2004). Isto porque o $\mathrm{N}$ aplicado no solo está sujeito a perdas por lixiviação, escorrimento superficial, desnitrificação, volatilização da amônia e pela imobilização na biomassa microbiana (ALVA et al., 2005).

Assim, o aumento da produtividade de grãos depende, entre outros fatores, da eficiência da absorção de $\mathrm{N}$ e sua translocação para os grãos em crescimento, onde ocorrerá a formação de compostos de reserva. Pesquisas sobre a avaliação dos mecanismos envolvidos na absorção de $\mathrm{N}$ mineral obtido de fertilizantes nitrogenados fornecidos via raiz, têm despertado interesse, tendo em vista a baixa eficiência na utilização do $\mathrm{N}$ mineral (WELLS \& TURNER, 1984). A suplementação nitrogenada via foliar é uma prática conveniente e rápida para melhorar as respostas ao mineral e, conseqüentemente, o crescimento da planta e para corrigir deficiências nutricionais em estádios da cultura onde a aplicação no solo torna-se ineficiente, tendo em vista o tempo de absorção e resposta (HARPER, 1984).

A maioria dos produtores de grãos reconhece a necessidade de um programa correto de manejo de nutrientes aplicados ao solo para alcançar as metas de produtividade. Pouco se conhece sobre as situações nas quais os fertilizantes foliares podem complementar os fertilizantes aplicados via solo, visando ao aumento da eficiência de uso do nutriente, da produtividade e lucratividade (CARVALHO et al., 2001).

Nos adubos foliares encontrados comercialmente, o $\mathrm{N}$ quase sempre está presente nas misturas com micronutrientes. Argumenta-se que a aplicação foliar é um meio eficiente de se fornecer $\mathrm{N}$ às plantas. Neste contexto, a uréia auxiliaria a absorção dos micronutrientes contidos na solução aplicada nas folhas, resultando em maior desenvolvimento e produtividade das plantas (BOARETTO et al., 1999). No entanto, pouco se conhece da aplicação de uréia via foliar como fonte isolada de $\mathrm{N}$ durante o estádio vegetativo de plantas de milho.

A uréia é indicada para adubação foliar por conter alto teor de $\mathrm{N}$, alto grau de solubilidade e baixa corrosividade. $\mathrm{O}$ risco de causar injúrias nas folhas é menor para a uréia em relação às outras fontes de $\mathrm{N}$, se comparadas soluções com concentrações equivalentes (BOARETTO et al., 1999).

Conduziu-se este trabalho, com o objetivo de verificar se a aplicação foliar de nitrogênio influencia o acúmulo de proteínas e parâmetros de crescimento de plantas jovens de milho em comparação com a aplicação de uréia via solo.

\section{MATERIAL E MÉTODOS}

No presente estudo foram utilizadas sementes do híbrido de milho BR 206 fornecidas pela Embrapa Clima Temperado e de uso comum no Estado do Rio Grande do Sul. O experimento foi conduzido em casa-de-vegetação e no Laboratório de Nutrição Mineral do Departamento de Botânica do Instituto de Biologia da Universidade Federal de Pelotas (UFPel). Em vasos de polietileno com capacidade para um litro, contendo $700 \mathrm{~g}$ de areia lavada como substrato, foram semeadas três sementes de milho e, aos sete dias após a emergência (DAE), foi realizado um desbaste deixando-se uma planta por vaso, sendo irrigadas com água sempre que necessário.

As plantas foram divididas em dois grupos: um para aplicação de $\mathrm{N}$ via foliar e outro para aplicação diretamente no substrato, para que o $\mathrm{N}$ fosse absorvido via raízes. A aplicação de $\mathrm{N}$ ocorreu na forma de solução de uréia nas concentrações de zero, $0,5 \%$ e 1,0\%. A aplicação foliar foi realizada com o auxílio de um pulverizador manual com capacidade para $500 \mathrm{~mL}$ e para evitar que a solução de uréia escorresse para o substrato e fosse absorvida via raiz, sacos plásticos foram colocados no interior de cada recipiente onde foi adicionado o substrato e, quando as pulverizações foram procedidas, os mesmos foram atados cuidadosamente ao caule. À solução de uréia fornecida via foliar foi adicionado um agente espalhante, Triton-X $0,1 \%$, para diminuir a tensão superficial e maximizar a eficiência de absorção.

Foram realizadas três aplicações de N, aos 6, 10 e 14 DAE. Na primeira, foram aplicados $10 \mathrm{~mL}$ e nas demais 20 $\mathrm{mL}$ por planta. Entre as aplicações de N, aos 8, 12 e 16 
DAE, foi fornecida às plantas uma solução nutritiva completa (HOAGLAND \& ARNON, 1938), exceto N, em volumes idênticos ao das soluções de uréia.

Aos 18 DAE as plantas foram coletadas, levadas ao laboratório e as análises foram procedidas. Inicialmente foi determinada a altura média das plantas com a ajuda de uma fita métrica e expressa em mm. Em seguida, as plantas foram separadas em parte aérea e raízes, sendo as folhas destacadas do colmo e estimada a área foliar $\left(\mathrm{cm}^{2}\right)$ por meio de um medidor de área modelo Li-cor 3100. A determinação do volume das raízes foi realizada por meio da medição do deslocamento da coluna de água em proveta graduada, ou seja, colocando-se as raízes, após lavagem, em proveta contendo um volume conhecido de água (100 $\mathrm{mL}$ ). Pela diferença, obteve-se a resposta direta do volume de raízes, pela equivalência de unidades $\left(1 \mathrm{~mL}=1 \mathrm{~cm}^{3}\right)$, segundo metodologia descrita por Basso (1999).

A seguir, as partes das plantas foram transferidas à estufa controlada para $75^{\circ} \mathrm{C}$ onde permaneceram por um período de 48 horas, para determinação da massa seca da parte aérea e raízes (mg).

Para a análise das proteínas, amostras de folhas e raízes foram coletadas e armazenadas em freezer a $-80^{\circ} \mathrm{C}$ até o momento de suas determinações. O teor de proteínas solúveis foi determinado em tecidos de folhas e raízes, conforme metodologia descrita por Bradford (1976). As leituras foram efetuadas em espectrofotômetro a $595 \mathrm{~nm}$ e comparadas com a curva-padrão de soro albumina bovina (BSA) 0,1 $\mathrm{g} \mathrm{L}^{-1}$, sendo o teor protéico da amostra expresso em $\mu \mathrm{g}$ de proteína por mg de matéria fresca.

$\mathrm{O}$ delineamento utilizado foi o inteiramente casualizado, em esquema fatorial $2 \times 3$, sendo duas formas de aplicação (foliar e via solo) e três concentrações de uréia (zero, $0,5 \%$ e 1,0\%). As médias de cinco repetições, após análise de variância, foram comparadas pelo teste de Duncan a $5 \%$ de probabilidade.

\section{RESULTADOS E DISCUSSÃO}

Na Figura 1, estão apresentados os valores médios de altura das plantas de milho cultivadas com diferentes níveis de uréia aplicada via foliar e via solo. Verificou-se que não houve efeito significativo da forma de aplicação de uréia, na concentração de $0,5 \%$, para o parâmetro avaliado. No entanto, quando a concentração aumentou para $1,0 \%$ de uréia, observou-se que a adubação foliar proporcionou um incremento na altura das plantas $26 \%$ superior ao observado quando a adubação ocorreu via raiz.

Para os diferentes níveis de uréia, observou-se que a aplicação via solo, proporcionou maior altura de plantas na concentração de $0,5 \%$ de uréia. No entanto, houve uma tendência a decréscimo na altura das plantas quando a concentração de uréia aumentou para $1,0 \%$, indicando que este pode ter sido um nível elevado ou tóxico de uréia, afetando negativamente a altura das plantas.

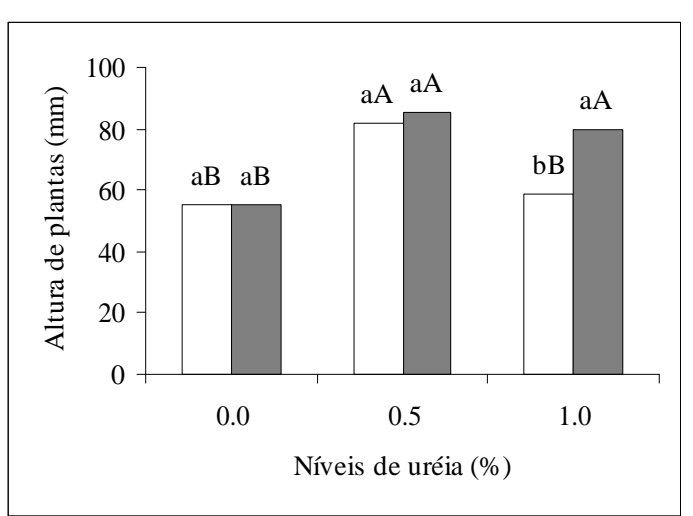

Figura 1 - Altura média das plantas de milho cultivadas com diferentes níveis de uréia aplicada via solo $(\square)$ e via foliar $(\square)$. Médias seguidas de uma mesma letra minúscula, dentro de cada nível, e maiúscula entre os níveis, não diferem entre si pelo teste de Duncan $(\mathrm{p} \leq 0,05)$.

Escosteguy et al. (1997) não encontraram diferenças significativas entre doses de aplicação do $\mathrm{N}$ na altura das plantas, quando se fez a aplicação integral ou o parcelamento nas doses de 80 e 160 kg.há ${ }^{-1}$ de N, em duas épocas de semeadura.

Quando o fornecimento de uréia ocorreu via foliar, não houve diferença entre os níveis 0,5 e 1,0\%, sendo que ambos proporcionaram valores superiores ao controle. Isto indica que o nitrogênio fornecido via foliar foi efetivamente absorvido e utilizado para o crescimento em altura das plantas. Segundo Arnon (1975), a deficiência de N retarda a divisão celular nos pontos de crescimento do milho, resultando em redução na área foliar e no tamanho da planta, com reflexos negativos sobre a produção.

Para o volume radicular dentro de cada nível de uréia (Figura 2), não houve diferença significativa entre as formas de aplicação, porém a melhor resposta, à semelhança do que ocorreu com a altura das plantas, também foi obtida para a concentração de $0,5 \%$ de uréia, comparando-se os níveis aplicados e o fornecimento via adubação foliar. Não houve diferença entre os níveis de uréia quando o fornecimento ocorreu via raiz.

Para o parâmetro área foliar das plantas (Figura 3), observou-se que a adubação foliar ao nível de $0,5 \%$ de uréia proporcionou uma área foliar 33\% superior em 


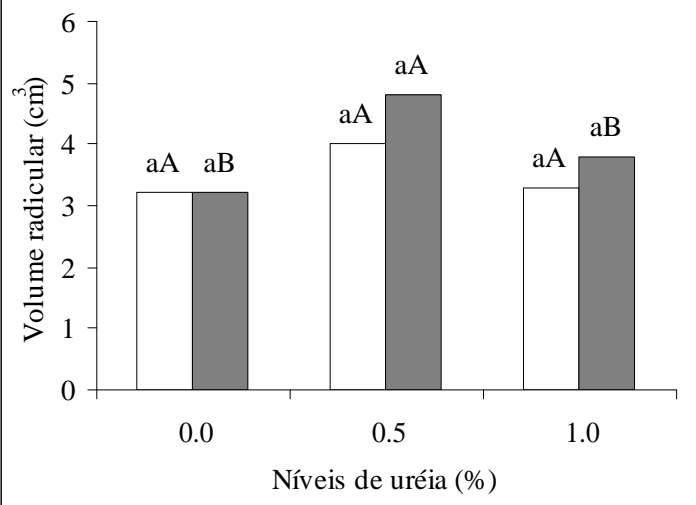

Figura 2 - Volume radicular de plantas de milho cultivadas com diferentes níveis de uréia aplicada via solo $(\square)$ e via foliar ( $\square$. Médias seguidas de uma mesma letra minúscula, dentro de cada nível, e maiúscula entre os níveis, não diferem entre si pelo teste de Duncan $(p \leq 0,05)$.

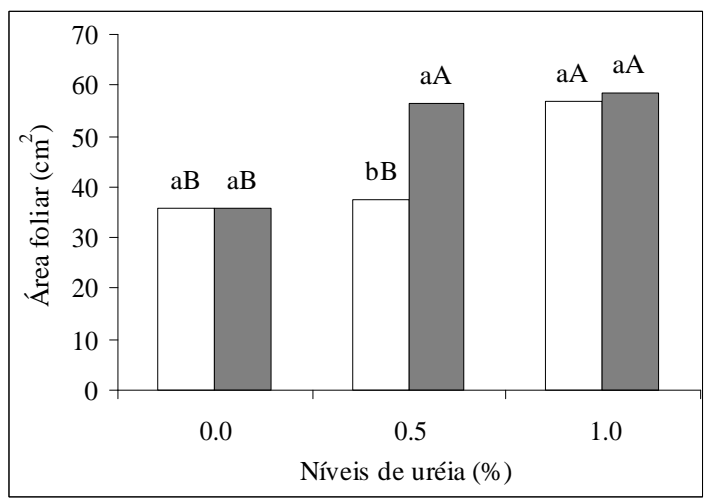

Figura 3 - Área foliar de plantas de milho cultivadas com diferentes níveis de uréia aplicada via solo $(\square)$ e via foliar (ם). Médias seguidas de uma mesma letra minúscula, dentro de cada nível, e maiúscula entre os níveis, não diferem entre si pelo teste de Duncan $(\mathrm{p} \leq 0,05)$.

comparação à aplicação via solo. Ao nível de 1,0\% de uréia aplicada não houve diferença entre os tratamentos para o desenvolvimento da área foliar, porém, esta foi significativamente superior às plantas controle.

Estes resultados de aplicação de $\mathrm{N}$ via solo discordam dos observados por Majerowicz et al. (2002) quando estudando a eficiência de uso do $\mathrm{N}$ em variedades de milho, observaram que a variedade BR 105 apresentou um aumento relativo de $222 \%$ na massa seca da parte aérea, tendo sido a dose de $\mathrm{N}$ elevada de $1 \mathrm{mM}$ para $15 \mathrm{mM}$. Alexandrino et al. (2004), estudando o efeito do N sobre características morfogênicas e anatômicas em Brachiaria brizantha $\mathrm{cv}$. Marandu, observaram que as doses de $20 \mathrm{e}$ $40 \mathrm{mg} \mathrm{dm}^{-3}$ semana $^{-1}$ de $\mathrm{N}$, promoveram incremento de $185 \%$ e $264 \%$ na taxa de alongamento foliar, respectivamente, em relação às plantas não adubadas. $\mathrm{O}$ incremento da produção de massa seca é, em grande parte, decorrente do aumento na taxa de alongamento foliar que está em função do aumento da área foliar.

A massa seca das raízes não apresentou diferença significativa para a forma de uréia aplicada. No entanto, comparando os dois níveis de uréia $(0,5 \%$ e $1,0 \%)$ com as plantas controle (sem uréia), observou-se incremento de aproximadamente $69 \%$ em relação à concentração de $0,5 \%$ e o controle (Figura 5).

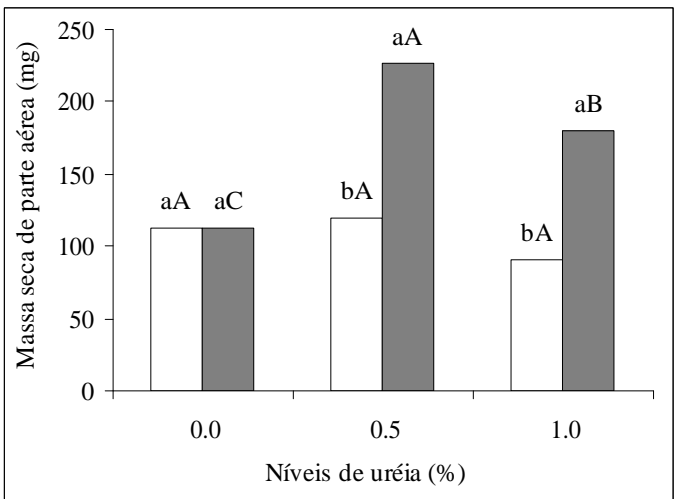

Figura 4 - Massa seca da parte aérea de plantas de milho cultivadas com diferentes níveis de uréia aplicada via solo ( $\square$ ) e via foliar ( $\square$ ). Médias seguidas de uma mesma letra minúscula, dentro de cada nível, e maiúscula entre os níveis, não diferem entre si pelo teste de Duncan $(\mathrm{p} \leq 0,05)$.

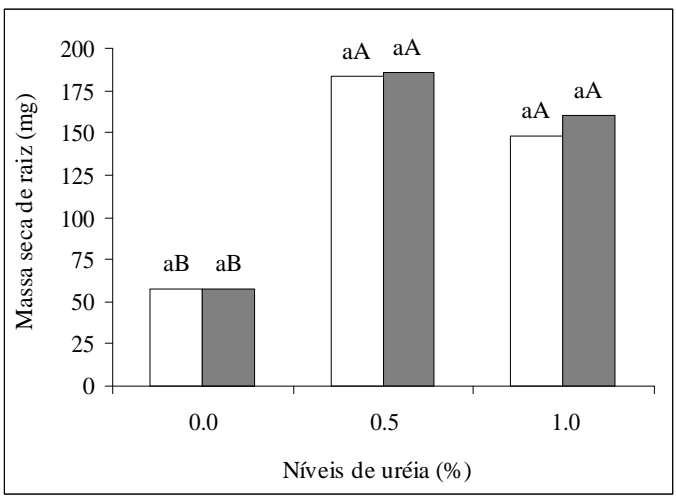

Figura 5 - Massa seca de raiz de plantas de milho cultivadas com diferentes níveis de uréia aplicada via solo $(\square)$ e via foliar ( $\square$ ). Médias seguidas de uma mesma letra minúscula, dentro de cada nível, e maiúscula entre os níveis, não diferem entre si pelo teste de Duncan $(\mathrm{p} \leq 0,05)$. 
Segundo Ta \& Weiland (1992) o N absorvido nos estádios iniciais apresenta principalmente função no sistema estrutural da planta, sendo, portanto, pouco armazenado e translocado. Binford et al. (1992) verificaram que a concentração de $\mathrm{N}$ nas plantas jovens tem relativamente pouco efeito sobre a produção final, não sendo um indicador confiável da disponibilidade de $\mathrm{N}$ nas plantas de milho.

Os teores de proteínas solúveis foram semelhantes nas folhas e raízes, exceto para a adubação via solo a 1,0\% de uréia, a qual proporcionou o maior incremento nas folhas (Figura 6). Isto demonstra que o fornecimento de $\mathrm{N}$ acarreta resultados diferenciados em relação ao teor de proteínas solúveis não apenas em função do estádio de desenvolvimento da planta e concentração do mineral, mas também em relação ao órgão vegetal.

A adubação foliar não foi eficiente em incrementar o teor de proteínas solúveis nas folhas. Entretanto, nas raízes houve uma diferença significativa entre as duas formas de aplicação da uréia, sendo que a aplicação foliar proporcionou maiores teores de proteínas em relação à aplicação via solo tanto a $0,5 \%$ quanto a $1,0 \%$ de uréia (Figura 7 ). Isto pode ter ocorrido em função da fácil translocação via floema de formas minerais de nitrogênio e do pequeno tamanho das plantas no estádio de desenvolvimento avaliado no presente experimento, tendo em vista que a capacidade de absorção e translocação de $\mathrm{N}$ varia em função da idade da planta e das folhas, sendo maior em plantas mais jovens.

Soares \& Restle (2002), estudando a adubação nitrogenada em pastagem de triticale mais azevém, verificaram um aumento linear no teor de proteína bruta com crescentes níveis de nitrogênio. Segundo Mazzanti et

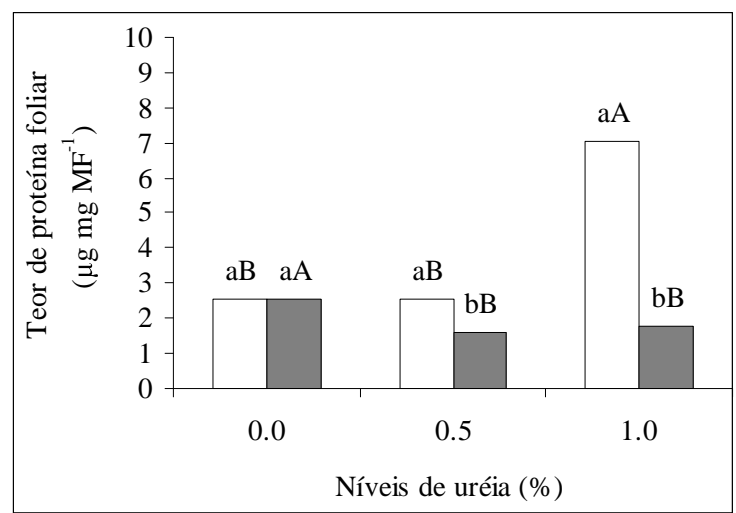

Figura 6 - Teor de proteína foliar em plantas de milho cultivadas com diferentes níveis de uréia aplicada via solo $(\square)$ e via foliar ( $\square$ ). Médias seguidas de uma mesma letra minúscula, dentro de cada nível, e maiúscula entre os níveis, não diferem entre si pelo teste de Duncan $(\mathrm{p} \leq 0,05)$.

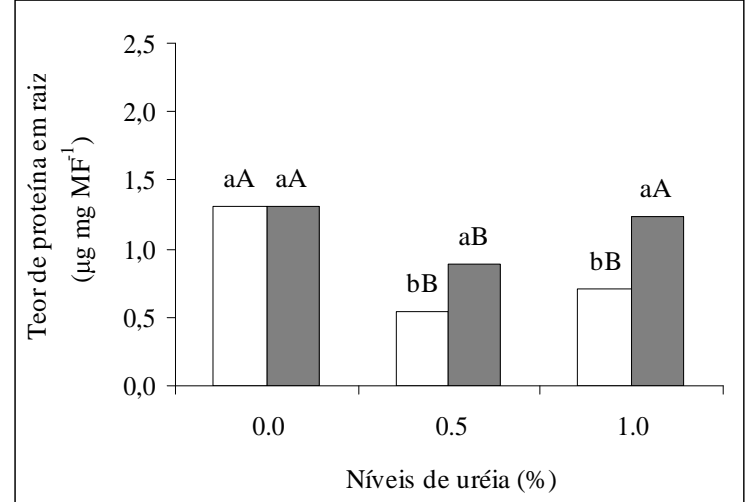

Figura 7 - Teor de proteína radicular em plantas de milho cultivadas com diferentes níveis de uréia aplicada via solo ( $\square$ ) e via foliar ( $\square$ ). Médias seguidas de uma mesma letra minúscula, dentro de cada nível, e maiúscula entre os níveis, não diferem entre si pelo teste de Duncan $(\mathrm{p} \leq 0,05)$.

al. (1997), é possível duplicar o teor de nitrogênio na planta, ao aumentar o nível de adubação nitrogenada de zero para $250 \mathrm{~kg} \mathrm{~N} \mathrm{ha}^{-1}$.

\section{CONCLUSÕES}

A aplicação de $\mathrm{N}$ via foliar pode ser uma maneira eficiente para complementar o que é absorvido pelas raízes, no entanto, não deve ser utilizada como única forma de fornecimento de $\mathrm{N}$ inorgânico às plantas e deve-se atentar para a concentração a ser utilizada, tendo em vista que pode ocorrer fitotoxicidade.

\section{REFERÊNCIAS BIBLIOGRÁFICAS}

ALEXANDRINO, E.; NASCIMENTO JÚNIOR, D. do; MOSQUIM, P. R.; REGAZZI, A. J.; ROCHA, F. C. Características morfogênicas e estruturais na rebrotação da Brachiaria brizantha cv.Marandu submetida a três doses de nitrogênio. Revista Brasileira de Zootecnia, Viçosa, v. 33, n. 6, p. 1372-1379, 2004.

ALVA, A. K.; PARAMASIVAM, S.; FARES, A.; DELGADO, J. A.; MATTOS JUNIOR, D.; SAJWAN, K. Nitrogen and irrigation management practices to improve nitrogen uptake efficiency and minimize leaching losses. Journal of Crop Improvement, Binghamton, v. 15, n. 2, p. 369-420, 2005.

ANDRADE, A. C.; FONSECA, D. M.; QUEIROZ, D. S.; SALGADO, L. T.; CECON, P. R. Adubação nitrogenada e potássica em capim-elefante (pennisetum purpureum schum. cv. napier). Ciência e Agrotecnologia, Lavras, p. 1643-1651, dez. 2003. Edição especial. 
ARNON, I. Mineral nutrition of maize. Bern: International Potash Institute, 1975.

BASSO, S. M. S. Caracterização morfológica e fixação biológica de nitrogênio de espécies de Adesmia DC. e Lotus L. 1999. 268 f. Tese (Doutorado em Zootecnia) Universidade Federal do Rio Grande do Sul, Porto Alegre, 1999.

BELARMINO, M. C. J.; PINTO, J. C.; ROCHA, G. P.; FERREIRA NETO, A. E.; MORAIS, A. R. de. Altura de perfilho e rendimento de matéria seca de capim-tanzânia em função de diferentes doses de superfosfato simples e sulfato de amônio. Ciência e Agrotecnologia, Lavras, v. 27, n. 4, p. 879-885, jul./ago. 2003.

BINFORD, G. D.; BLACKMER, A. M.; CERRATO, M. E Nitrogen concentration of young corn plants as an indicator of nitrogen availability. Agronomy Journal, Madison, v. 84, p. 219-223, 1992.

BOARETTO, A. E.; SANTOS NETO, P.; MUROAKA, T.; OLIVEIRA, M. W.; TRIVELIN, P. C. O. Fertilização foliar de nitrogênio para laranjeira em estágio de formação. Scientiae Agrícola, 1999.

BOTREL, M. A.; ALVIM, M. J.; MARTINS, C. E. Aplicação de nitrogênio em acessos de Brachiaria. 2. Efeito sobre os teores de proteína bruta e minerais. Pasturas Tropicales, Cali, v. 12, n. 2, p. 7-10, ago. 1999.

BRADFORD, M. M. A rapid and sensitive method for the quantitation of microgram quantities of protein utilizing the principle of protein-dye binding. Analytical Biochemistry, v. 72, p. 248-254, 1976.

CARVALHO, M. A. C. de; PAULINO, H. B.; FURLANIJUNIOR, E.; BUZETTI, S.; SÁ, M. E. de; ATHAYDE, M. L. F. de. Uso da adubação foliar nitrogenada e potássica no algodoeiro. Campinas: Bragantia, 2001.

DÖBEREINER, J.; BALDANI, V. L. D.; BALDANI, J. I. Como isolar e identificar bactérias diazotróficas de plantas não leguminosas. Brasília, DF: Embrapa-SPI; Itaguaí: EmbrapaCNPAB, 1995. $60 \mathrm{p}$.

ESCOSTEGUY, P. A. V.; RIZZARDI, M. A.; ARGENTA, G. Doses e épocas de aplicação de nitrogênio em cobertura na cultura do milho em duas épocas de semeadura. Revista Brasileira de Ciência do Solo, Campinas, v. 21, p. 71-77, 1997.
GASTAL, F.; LEMAIRE, G. Nuptake and distribution in crops: an agronomical and ecophysiological perspective. Journal of Experimental Botany, v. 53, n. 370, p. 789-799, 2002

GASTAL, F.; NELSON, C. J. Nitrogen use within the growing leaf blade of tall fescue. Plant Physiology, v. 105, p. 191-197, 1994.

HARPER, J. E. Uptake of organic nitrogen forms by roots and leaves. In: HAUCK, R. D. (Ed.). Nitrogen in crop production. Wisconsin: American Society of Agronomy, 1984. p. $165-170$

HOAGLAND, D. R.; ARNON, D. I. The water-culture method for growing plants without soil. In:

Agricultural experiment station. California: University of California, 1938. p. 1-39. (Circular, 347).

LARA CABEZAS, W. A. R.; ALVES, B. J. R.; URQUIAGA, S.; SANTANA, D. G. de. Influência da cultura antecessora e da adubação nitrogenada na produtividade de milho em sistema plantio direto e solo preparado. Ciência Rural, Santa Maria, v. 34, p. 1005-1013, 2004.

MAJEROWICZ, N. et al. Estudo da eficiência de uso do nitrogênio em variedades locais e

melhoradas de milho. Revista Brasileira de Botânica, São Paulo, v. 25, n. 2, p. 129-136, 2002.

MARTUSCELLO, J. A. et al. Características morfogênicas e estruturais do capim-xaraés submetido à adubação nitrogenada e desfolhação. Revista Brasileira de Zootecnia, Viçosa, v. 34, n. 5, p. 1475-1482, 2005.

MAZZANTI, A.; MARINO, M. A.; LATTANZI, F. Efecto de la fertilización nitrogenada sobre el crecimiento y la calidad del forraje de Avena y Raigrás anual en el sudeste Bonariense. Montivideu: INTA, 1997. (Boletim técnico, 143).

RAUN, W. R.; JOHNSON, G. V. Improving nitrogen use efficiency for cereal production. Agronomy Journal, Madison, v. 91, n. 3, p. 357-363, 1999.

SCHRÖDER, J. J. et al. Does the crop or the soil indicate how to save nitrogen in maize production?: reviewing the state of art. Field Crops Research, Amsterdam, v. 66, n. 1, p. $151-164,2000$ 
SKINNER, R. H.; NELSON, C. J. Elongation of the grass leaf and its relationship to the phyllochron. Crop Science, Madison, v. 35, p. 4-10, 1995.

SOARES, A. B.; RESTLE, J. Adubação nitrogenada em pastagem de triticale mais azevém sob pastejo com lotação contínua: recuperação de nitrogênio e eficiência na produção de forragem. Revista Brasileira de Zootecnia, Viçosa, v. 31, n. 1, 2002.
TA, C. T.; WEILAND, R. T. Nitrogen partitioning in maize during ear development. Crop Science, Madison, v. 32, p. 443-451, 1992.

WELLS, B. R.; TURNER, F. T. Nitrogen use in flooded rice soils. In: HAUCK. R. D. (Ed.). Nitrogen in crop production. Wisconsin: American Society of Agronomy, 1984. p. 349362 . 